In-pore exchange and diffusion of carbonate solvent mi tueaveithisareạ blank formabstract info. Todd M. Alam, Thomas M. Osborn Popp

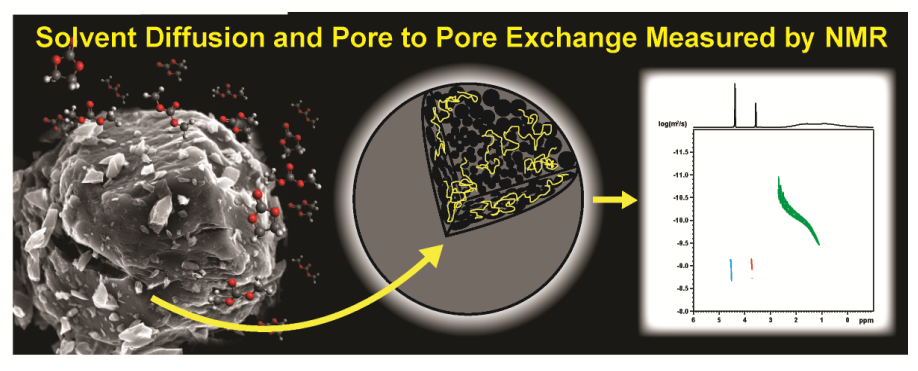


Chemical Physics Letters

journal homepage: www.elsevier.com

\title{
In-pore exchange and diffusion of carbonate solvent mixtures in nanoporous carbon
}

\author{
Todd M. Alam ${ }^{\mathrm{a},}$, Thomas M. Osborn Popp ${ }^{\mathrm{a}, \mathrm{b}}$ \\ ${ }^{a}$ Department of Organic Materials Science, Sandia National Laboratories, Albuquerque, NM 87185, USA \\ ${ }^{b}$ Department of Chemistry, University of California Berkeley, Berkeley, CA 94720, USA
}

\section{ARTICLE INFO}

\section{ABSTRACT}

Article history:

Received

Received in revised form

Accepted

Available online

Keywords:

${ }^{1} \mathrm{H}$ NMR

Diffusion

PFG

HR-MAS

Porous Carbon

Supercapacitor
High resolution magic angle spinning (HRMAS) ${ }^{1} \mathrm{H}$ NMR spectroscopy has been used to resolve different surface and in-pore solvent environments of ethylene carbonate (EC) and dimethyl carbonate (DMC) mixtures absorbed within nanoporous carbon (NPC). Two dimensional (2D) ${ }^{1} \mathrm{H}$ HRMAS NMR exchange measurements revealed that the inhomogeneous broadened in-pore resonances have pore-to-pore exchange rates on the millisecond timescale. Pulsed-field gradient (PFG) NMR diffusometry revealed the in-pore self-diffusion constants for both EC and DMC were reduced by up to a factor of five with respect to the diffusion in the non-absorbed solvent mixtures.

2016 Elsevier Ltd. All rights reserved.

\section{Introduction}

Currently there is a growing need for energy storage technologies for application in electric vehicles, mobile electronic devices, and grid energy storage. Electrochemical capacitors, often known as supercapacitors, are a promising energy storage candidate for uses where rapid delivery of high power is required [1-3]. The class of supercapacitors known as electrochemical double layer capacitors (EDLC) use porous, high surface area, carbon electrodes immersed in a liquid electrolyte to achieve charge separation resulting in high capacitance and high power density, but with lower energy density than lithium-ion batteries [4]. To achieve higher energy densities and yet still maintain high power density, lithium-ion capacitors (LIC) have been developed which aim to bridge the gap between batteries and supercapacitors [5-9]. During charging and discharging of an LIC, lithium ions intercalate in and out of a graphite negative electrode, while anions adsorb and desorb to and from the surface of the positive electrode. The positive electrode is usually made from a porous carbon material. Electrolyte solvents for EDLC and LIC commonly involve mixtures of carbonate solvents, including the 1:1 mixture of ethylene carbonate (EC) and dimethyl carbonate (DMC). Carbonate solvents readily dissolve

* Corresponding author. Tel: 1-505-844-1225

E-mail address: tmalam@sandia.gov (T.M. Alam) lithium ions, operate within a large electrochemical window, form a very stable solid electrolyte interphase (SEI) layer on the graphite negative electrode, and are considered "green" solvents due to their relative non-toxicity and the fact that they can be synthesized using $\mathrm{CO}_{2}$ as a feedstock [9-11].

Activated carbon (AC) and nanoporous carbon (NPC) materials are ideal electrode materials for symmetric EDLC, and for the positive electrode in asymmetric LICs, due to their high conductivity and surface area [12-15]. These carbon materials are comprised of $\mathrm{sp}^{2}$-hybridized graphene-like sheets organized in a porous, amorphous structure [16,17]. Ultimately it is the transport and adsorption of ions in NPC that determines the EDLC and LIC power storage and discharge characteristics. The contributions that surface area, surface defects, pore size distributions, pore tortuosity, pore alignment, electrolyte diffusion, and solvent shell rearrangement have on ion transport within carbonaceous materials remains a topic of debate [18-22]. These questions have led to the development of many different NPC systems with specific tailored surface and pore properties [15,19,22-25]. Understanding the interactions between electrolyte molecules and porous carbon electrode materials is critical to improving the design of EDLCs and LICs, in particular the rate of transport of the electrolytes within the electrodes.

Nuclear magnetic resonance (NMR) spectroscopy provides a noninvasive and highly selective method for probing these interactions. Previous NMR studies of electrolytes in porous carbon materials have focused on the adsorption, organization, and degree of infiltration of ions within the pores [20,26-31]. Large changes in the chemical shift of electrolyte molecules occur upon adsorption into a porous carbon material as a result of diamagnetic ring current effects, making it experimentally straightforward to isolate and study populations of molecules 
inside and outside of the pores [26-29,32,33]. These unique poreinduced NMR chemical shifts have recently allowed the breakdown of electroneutrality and the ion dehydration process in aqueous nanoconfined systems to be directly measured $[34,35]$. Due to the heterogeneity of porous carbon samples, the NMR resonances of these pore-absorbed electrolytes are commonly broadened due to variations in the local magnetic susceptibility, and can make spectral separation of different chemical species difficult.

In this paper, high resolution magic-angle spinning (HRMAS) NMR was employed to improve the spectral resolution for carbonate solvent mixtures absorbed in NPC. MAS averages the line broadening from heterogeneity in the isotropic magnetic susceptibility, residual dipolar coupling and chemical shift anisotropy and has been useful in studying liquid-like species within materials [36,37]. The interactions between electrolytes and porous carbon electrodes may be characterized by observing changes in the electrolyte and solvent translational diffusion (transport) inside and outside of the pores of the electrode material. NMR diffusometry measurements employing pulsed field gradient (PFG) techniques provide a measure of the molecular self-diffusion in equilibrated system for the different chemical species present [38,39]. While there have been several NMR and molecular dynamics studies examining the selfdiffusion of molecules within porous carbon materials [40-43], few studies have examined the diffusion of electrolyte components in a NPC system relevant to supercapacitor and LIC applications $[44,45]$, and no studies have directly measured the transport of individual chemical species in absorbed carbonate solvent mixtures. By combining ${ }^{1} \mathrm{H}$ HRMAS NMR with diffusometry techniques an improved understanding of solvent interactions and transport inside the pores of the carbon electrodes can be developed.

\section{Experimental}

Nanoporous carbon (NPC) powder was obtained from ACS Material (Medford, MA) with a nominal pore size ranging between 2.0 and $2.2 \mathrm{~nm}$, particle size between 5 and $8 \mu \mathrm{m}$, and surface area of $2238 \mathrm{~m}^{2} / \mathrm{g}$. Details of the BET isotherm and SEM experimental are provided in the supplemental material (Figures $\mathrm{S} 1-\mathrm{S} 3$ ). The NPC powder was activated at $200{ }^{\circ} \mathrm{C}$ under vacuum for 24 hours. Ethylene carbonate (EC, Sigma Aldrich, 99\%, anhydrous) and dimethyl carbonate (DMC, Sigma Aldrich, 99\%, anhydrous) were mixed in a 1:1 molar ratio. Samples of DMC or the EC/DMC mixture was absorbed into NPC at different wt $\%$. Loadings were prepared by direct mixing in $30 \mu \mathrm{l} \mathrm{Kel-F} \mathrm{HRMAS}$ inserts (Bruker Biospin Inc.) prior to sealing and insertion into 4 $\mathrm{mm}$ zirconia MAS rotors. These included the $1: 1$ and $4: 1$ DMC:NPC and the $1: 1,2: 1$ and $4: 1$ (EC/DMC):NPC samples. The high solvent loaded samples demonstrated a slow evolution to an equilibrated state as a function of time and spinning conditions (see Figures S4-S6, supplemental material).

${ }^{1}$ H HRMAS NMR spectra were obtained on a Bruker Avance III 14.1 T NMR spectrometer operating at a proton frequency of $600.18 \mathrm{MHz}$ using a triple resonance ${ }^{1} \mathrm{H}-{ }^{13} \mathrm{C}-{ }^{31} \mathrm{P}$ HRMAS probe with gradient strengths of $0.53 \mathrm{~T} / \mathrm{m}$. ${ }^{1} \mathrm{H}$ chemical shifts were referenced to $\mathrm{H}_{2} \mathrm{O}(298 \mathrm{~K})$ at $\delta=4.7 \mathrm{ppm}$, with respect to TMS at $\delta=0 \mathrm{ppm}$. All $1 \mathrm{D}{ }^{1} \mathrm{H}$ NMR spectra were obtained using a single pulse Bloch decay with 8 scan averaging, a $8 \mu \mathrm{s} \pi / 2$ excitation pulse length, and $10 \mathrm{~s}$ relaxation delay. Measurements of transverse relaxation $\left(\mathrm{T}_{2}\right)$ for ${ }^{1} \mathrm{H}$ were collected using the Hahn spin echo experiment, using 16 delay increments with 8 scans per increment. NMR PFG diffusion measurements were performed on equilibrated samples using the 13-interval stimulated echo sequence employing $1 \mathrm{~ms}$ trapezoid shaped bipolar diffusionencoding gradient pulses of length $\delta$, variable diffusion times $(\Delta)$ between 100 and $500 \mathrm{~ms}, 32$ gradient strengths $(q)$ between $2 \%$ and $98 \%$ of the maximum gradient power, with 8 scan averages per gradient increment. To extract the diffusion constant $(D)$, the echo decay as a function of gradient strength $[E(q, \Delta)]$ was evaluated using the standard Stejskal-Tanner relationship [2]

$$
E(q, \Delta) / E(0, \Delta)=\exp \left[-q^{2} D(\Delta-\delta / 3)\right]
$$

The error in $D$ was estimated from the standard deviation of multiple experiments with different $\Delta$ delays. For the range of diffusion delays investigated, $D$ was found to be independent of $\Delta$ and therefore represents the tortuosity diffusion limit $[46,47]$. The 2D ${ }^{1} \mathrm{H}-{ }^{1} \mathrm{H}$ EXSY (exchange spectroscopy) NMR experiments were obtained for different mixing periods $\left(\tau_{\text {mix }}\right)$, with 8 scan averages, and $512-1024 \mathrm{t}_{1}$ increments. Spectral deconvolutions were performed using the DMFIT software [48].

\section{Results and Discussion}

Representative ${ }^{1} \mathrm{H}$ HRMAS NMR spectra for the different carbonate solvent and NPC mixtures are shown in Figure 1, with the chemical shifts and line width (FWHM = Full Width at Half Maximum) summarized in Table 1. Upon adsorption of DMC into NPC, an asymmetrically broadened resonance (FWHM $540 \mathrm{~Hz}$ ) appeared at $\delta=+0.56 \mathrm{ppm}$, which is $3.05 \mathrm{ppm}$ lower than the very narrow neat solvent peak $(\mathrm{FWHM}=5 \mathrm{~Hz})$. This broad resonance was assigned to DMC solvent inside the pores of the NPC (in-pore). For the 4:1 DMC:NPC mixture, multiple resonances were obtained and were assigned to the free, surface adsorbed and in-pore absorbed DMC environments (Table 1). The resonances for the free and in-pore different environments in the non-spinning static spectra were very broad, overlapping and unresolved, while under MAS conditions these different environments were easily resolved (Figure 1). The shift to lower frequency of the in-pore solvent resonance is related to its proximity to the carbon pore walls [28]. Ring currents arising from electron motions in the $\mathrm{sp}^{2}$-hybridized orbitals of the carbon induce a local magnetic field that opposes the main external field at the site of the nucleus, resulting in an increased shielding (lower frequency) chemical shift. The NICS (Nuclear Independent Chemical Shift) in NPC has been modeled and is indicative of the distance from the carbon surface [28]. Since solvent diffusion inside the NPC pores is relatively rapid (see later diffusion discussion) the experimental NMR chemical shift reflects the motional averaging over different spatial positions of the solvent within the pore, and can be related to the average pore size dimension [31]. The NICS observed for DMC in NPC (Table 1 ) is consistent with that for nuclei centrally located between two circumcoronene molecules (slit pore model) separated by $2 \mathrm{~nm}$, or with solvent nuclei inside a $2.3 \mathrm{~nm}$ pore based on the chemical shift to pore size correlation (see supplemental material) developed by Xing and co-workers [31]. Merlet et al. showed via a lattice model method that the broadness of the peak arises from exchange between pores of different sizes, and thus different chemical shifts [49]. Their model of a porous carbon with a random spatial distribution of various pore sizes resulted in a symmetrically broadened line. However, a spatial gradient of differing pore size in the NPC particles results in an asymmetric, inhomogeneously broadened line shape due to diffusion-limited exchange between differently sized pores on the NMR timescale, as experimentally observed in the ${ }^{1} \mathrm{H}$ HRMAS NMR of DMC in NPC. This pore-exchange argument is further confirmed by the 2D ${ }^{1} \mathrm{H}$ NMR exchange experiments described below. At the higher 4:1 DMC:NPC solvent loadings the outer surface (or interparticle) environment revealed significantly smaller NICS $(\sim$ $0.47 \mathrm{ppm}$ ), corresponding to an average pore dimension of 10.6 $\mathrm{nm}$. The variation of pore size with NICS is very large for this range of pore sizes, thus producing a large error bar for the pore size estimate. This solvent signal most likely arises from DMC molecules adsorbed on inter-particle surfaces or absorbed in large meso-pores or defects that are in rapid exchange with solvent in neighboring pores, but will be referred to as surface species in the present discussion. The NICS is reduced to $-1.89 \mathrm{ppm}(3.3 \mathrm{~nm})$ 
for the in-pore species in the 4:1 DMC:NPC mixture (Table 1) in comparison to the 1:1 sample, again revealing that exchange and partial chemical shift averaging between the surface and in-pore environments are occurring for samples containing excess solvent. This incomplete coalescence of the in-pore and surface resonances also argues that only a portion of the external surface solvent has direct access to the in-pore environment on the NMR time scale. The observation of separate signals (with a frequency separation of $\Delta v$ ) for free, surface and in-pore species at higher DMC loadings (see 4:1 DMC:NPC, Figure 1) provides an upper limit on the exchange rate of $k<300 \mathrm{~s}^{-1}(k<\Delta v)$ for complete averaging between free and the surface adsorbed environments, and $k<1135 \mathrm{~s}^{-1}$ between the free and in-pore environments.

Adsorption of the 1:1 EC/DMC solvent mixture into NPC at different loading shows similar behavior with both the free and in-pore environments being resolved in the ${ }^{1} \mathrm{H}$ HRMAS NMR (Figure 1). In the 1:1 sample the NICS for the in-pore DMC was $2.70 \mathrm{ppm}$ corresponding to an average $2.5 \mathrm{~nm}$ pore size, while the NCIS of the EC component was -3.11 ppm representing a $2.3 \mathrm{~nm}$ pore. There is a minor reduction in the average NICS with increased loading (Table 1).

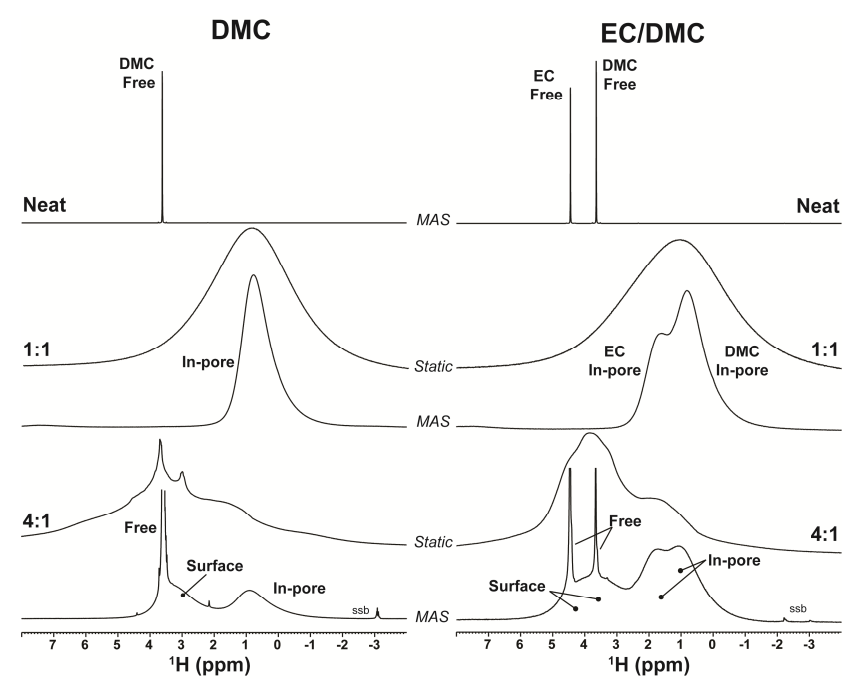

Figure 1: ${ }^{1} \mathrm{H}$ HRMAS NMR spectra for DMC and EC/DMC (1:1 molar) solvent mixtures, plus spectra of solvent mixtures absorbed in nanoporous carbon at different weight ratios $(\mathrm{ssb}=$ spinning sidebands).

Since the asymmetric line shapes are the result of distributions in the average pore size, the deconvoluted EC:DMC NMR spectrum (Figure 2) allow the pore size distribution (PSD) to be extracted using the method of Xing and co-workers [31] (additional discussion in supplemental) and are shown in Figure 2b. The PSD for EC and DMC are nearly identical, and are consistent with a model where the solvent mixture explores a range of pore sizes between $\sim 1 \mathrm{~nm}$ and $5 \mathrm{~nm}$. It has been suggested that the correlation used for this PSD analysis is only approximate, with the magnitude of the NICS being dependent on the aromatic nature of the adjacent surface [30]. Regardless, these types of HRMAS NMR experiments clearly reveal that the NPC material has a range of pore sizes in the nanometer range. The NMR PSD distribution is equivalent with the range reported by the material supplier and the $\mathrm{N}_{2}$ BET results, but did not reveal the bimodal PSD extracted from the Ar BET analysis (Figure S2). These NMR results can be used to address the NPC electrochemical performance. For example, the PSD extracted from the NMR NICS of the absorbed solvent revealed pore sizes spanning the microporous $(<2 \mathrm{~nm})$ and mesoporous $(2$ to $50 \mathrm{~nm})$ regime. The filled micropores contribute to the high surface area portion of EDLC capacitance, but may also impact the capacitance via restricted diffusion effects along with increased adsorption affinity of solvent and electrolytes for these smaller pores. These results also suggest that the pore sizes $<1.4 \mathrm{~nm}$ detected using BET may not be fully accessible by typical carbonate solvents. This inaccessible pore surface area would not be utilized electrochemically (most notably for solvated electrolytes), making the BET derived surface area a poor measure of the true electrochemically active surface area in comparison to this NMR method. The presence of mesopores in the NPC also contributes to the high surface area component of capacitance. These larger pores should also provide regions of improved diffusion and accessibility of the solvent (or solvated ion) within the NPC $[15,24]$. The similarity of the PSD measured for $\mathrm{EC}$ and $\mathrm{DMC}$ in the solvent mixture demonstrates that the same pore environments were accessible to these solvents and that in equilibrated materials no preferential pore-absorption of one component was occurring (i.e. no size selection).

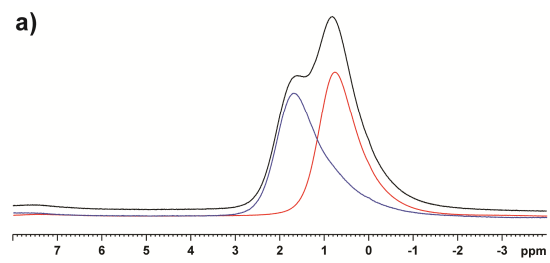

b)

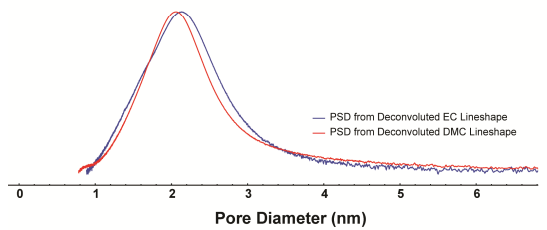

Figure 2: ${ }^{1} \mathrm{H}$ HRMAS NMR of EC/DMC electrolyte mixture absorbed (1:1) in NPC with the (a) spectral deconvolutions of the individual EC (blue) and DMC (red) spectral components and (b) corresponding pore size distributions extracted from the NMR

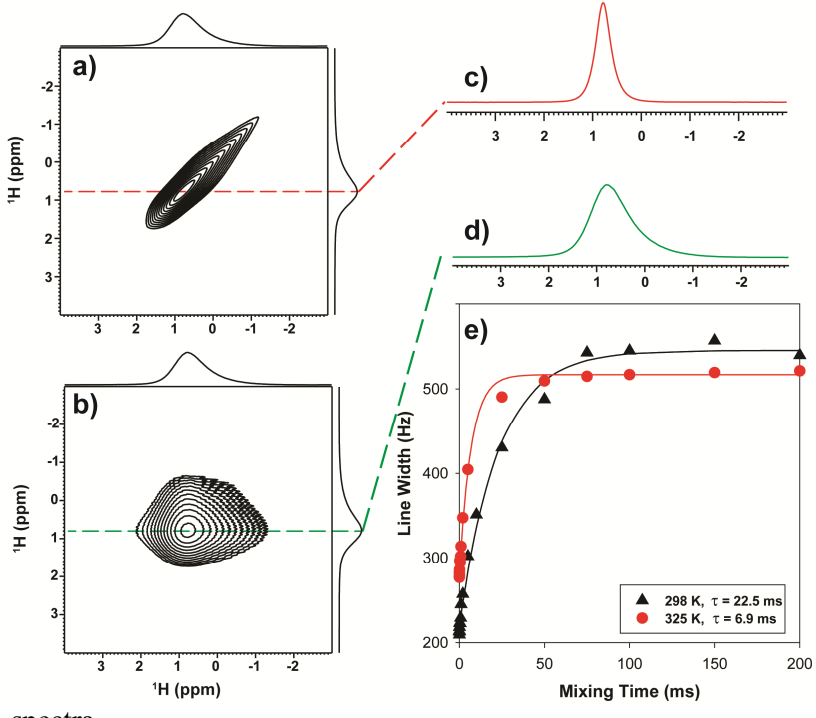

spectra.

Figure 3: 2D ${ }^{1} \mathrm{H}$ HRMAS NMR exchange spectra of the DMC solvent absorbed in nanoporous carbon (1:1)for a) $10 \mu \mathrm{s}$ and b) $100 \mathrm{~ms}$ mixing times, with c) and d) being 1D slices extracted along the DMC peak maximum, along with e) the variation of line width as a function of mixing time.

2D ${ }^{1} \mathrm{H}$ HRMAS NMR EXSY experiments revealed the exchange of solvent between the multiple NPC environments (Figure 3). In the spectrum of 1:1 DMC:NPC at a short mixing time $\left(\tau_{\text {mix }}=10 \mu \mathrm{s}\right.$, Figure $\left.3 \mathrm{a}\right)$ the observed signal is concentrated along the diagonal, with a narrower isotropic (FWHM $\sim 210 \mathrm{~Hz}$ ) 
resonance observed for each different chemical shift. A slice through the peak maximum is shown in Figure 3c. This experimentally demonstrates that the asymmetric in-pore NMR resonances are inhomogeneously broadened and result from the distribution of chemical shift and corresponding pore sizes. There remains a $210 \mathrm{~Hz}$ residual homogeneous broadening that is either produced from dynamic exchange or incomplete averaging of the magnetic susceptibility. It is important to note that anisotropic magnetic susceptibility is not completely averaged by MAS while the isotropic component of magnetic susceptibility is averaged under MAS [37]. For solvent molecules near the graphene-like surface of NPC the anisotropy is expected to be significant. For longer mixing times $\left(\tau_{\text {mix }}=100 \mathrm{~ms}\right)$ the 2D NMR correlation peak broadens (Figure 3b) with the line width increasing to 540 $\mathrm{Hz}$. This increasing linewidth is a result of the DMC solvent exploring pores with different average sizes (i.e. different average NICS). At long mixing times the signal further broadens to an asymmetric resonance encompassing all chemical shifts observed in the original 1D spectrum (Figure 1). The variation of the line width as a function of mixing time is shown in Figure 3e, and was modeled using an exponential function. At $298 \mathrm{~K}$ the observed pore-to-pore exchange has a time constant of $\tau \sim 22.5 \mathrm{~ms}(\mathrm{k} \sim 44$ $\mathrm{s}^{-1}$ ), while at $325 \mathrm{~K}$ the exchange process increased with an estimate time constant of $\tau \sim 7 \mathrm{~ms}\left(\mathrm{k} \sim 143 \mathrm{~s}^{-1}\right)$. Similarly the 2D NMR exchange spectra for the EC/DMC mixture absorbed in NPC (Figure 4) shows that both the EC and DMC resonances are inhomogeneously broadened with a time constant of $\tau \sim 35 \mathrm{~ms}(\mathrm{k}$ $\left.\sim 28 \mathrm{~s}^{-1}\right)$ for DMC and $\tau \sim 45 \mathrm{~ms}\left(\mathrm{k} \sim 22 \mathrm{~s}^{-1}\right)$ for EC. Combining these pore-to-pore exchange rates with the measured in-pore diffusion constants ( $D$ discussed later) suggests a length scale ( $l \sim$ $(2 D)^{1 / 2}$ ) between 5 and $10 \mu \mathrm{m}$, which is the same magnitude as the measured particle sizes. These exchange results reveal that the solvent explores essentially the entire distribution of pore sizes during the $2 \mathrm{D}$ experiments with all the different pore sizes being present in each NPC particle.

The exchange between different solvent environments in the NPC materials with higher solvent loading were also explored using $2 \mathrm{D}{ }^{1} \mathrm{H}$ NMR exchange experiments. Figure 5 shows an example for the 4:1 (EC/DMC):NPC sample where the exchange between the in-pore solvent environment and the surface solvent environments for both the DMC and EC are readily observed as off diagonal resonances at higher mixing times. Exchange between the in-pore and surface environments for the high DMC:NPC loading was also observed (Figure S7). The time constants for the surface to in-pore solvent exchange for EC and DMC are very similar ( 6 to $10 \mathrm{~ms}$ ), but are both faster than the in-pore to in-pore exchange rate. The faster exchange rate might be expected for surface (inter-particle) solvent transport (Figure S8).

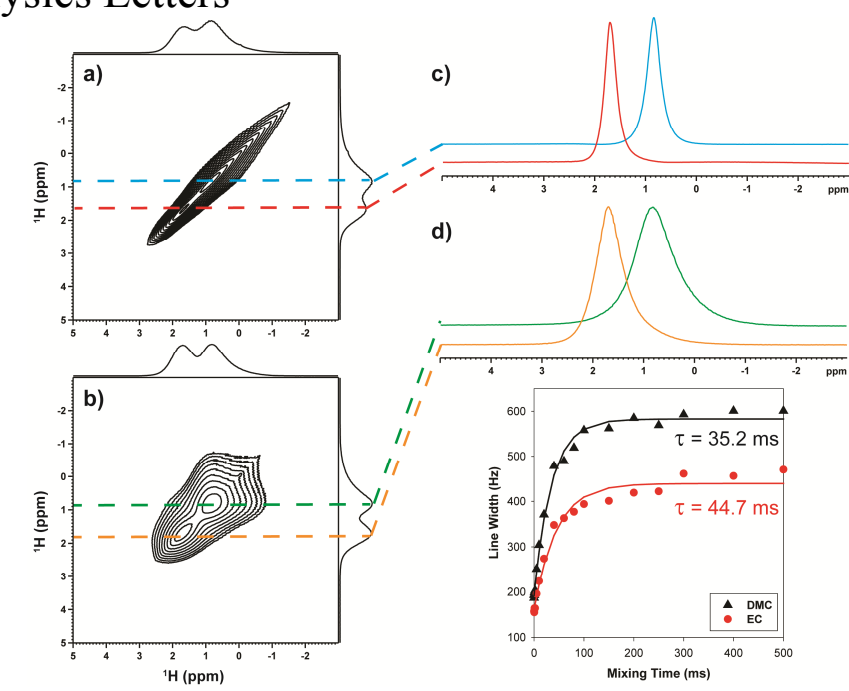

Figure 4: $2 \mathrm{D}{ }^{1} \mathrm{H}$ NMR exchange spectra of the EC/DMC (1:1) electrolyte absorbed into NPC (1:1) for a) $10 \mu \mathrm{s}$ and b) $100 \mathrm{~ms}$ mixing times, with extracted $1 \mathrm{D}$ slices c) and d) at the maximum EC and DMC chemical shifts, plus e) the variation of the linewidth as a function of mixing time for the two solvent species.

Solvent diffusion was measured using ${ }^{1} \mathrm{H}$ PFG HRMAS NMR for the $\mathrm{EC}$ and $\mathrm{DMC}$ solvent mixtures under various conditions and loadings as summarized in Table 1. The self-diffusion coefficient for neat DMC was $2.7 \cdot 10^{-9} \mathrm{~m}^{2} \mathrm{~s}^{-1}$ at $298 \mathrm{~K}$, and the coefficient for neat EC was $1.9 \cdot 10^{-9} \mathrm{~m}^{2} \mathrm{~s}^{-1}$ at $315 \mathrm{~K}$; both are consistent with previously reported values [30]. The 2D DOSY experiment for the 1:1 DMC:NPC (Figure 6, red) allowed the inpore diffusion rate for DMC to be measured at 5.6 $10^{-10} \mathrm{~m}^{2} \mathrm{~s}^{-1}$, giving a reduction ratio or tortuosity $\left(\mathrm{D} / \mathrm{D}_{0}\right)$ of $\sim 0.21$. This reduction is due to the hindered diffusion within the NPC pores. The diffusion is relatively uniform across the range of chemical shifts spanned by the in-pore DMC resonance (Figure 6). The diffusion length scale is given by $l_{\mathrm{D}} \sim(2 \Delta D)^{1 / 2}$ and for PFG NMR experiments using a $\Delta=100 \mathrm{~ms}$ diffusion delay, the length scale probed was $\sim 10 \mu \mathrm{m}$, on the order of the particle dimensions (Figure S3). The observed diffusion coefficients are therefore an average over different diffusion environments occurring in multiple pores, and reflect not only the in-pore diffusion rate but the in-pore to in-pore exchange process (discussed in the $2 \mathrm{D}$ NMR experiments described above). It is well known that restricted diffusion will produce $D$ values that are $\Delta$ dependent $[46,47]$. In the current study, variations in $D$ were not observed for the $\Delta$ range of studied (100 to $500 \mathrm{~ms}$ ). The measured $D$ therefore represents the tortuosity diffusion limit. To probe restricted diffusion occurring within only a single $2 \mathrm{~nm}$ pore would require the use of very short $\Delta$ values, which are experimentally hampered by the lack of signal decay (Eqn. 1.1), or the use of gradient strengths significantly larger than the current hardware allows. 


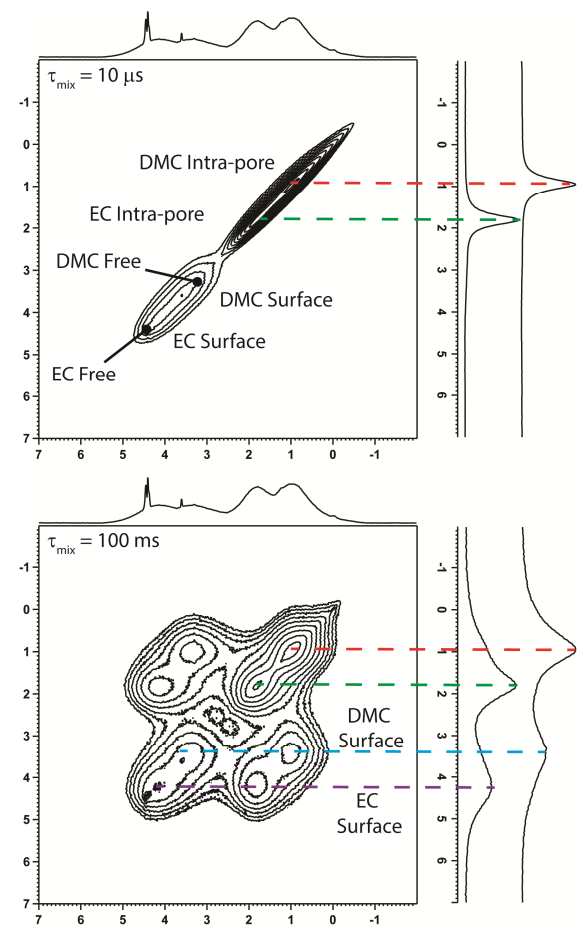

Figure 5: $2 \mathrm{D}{ }^{1} \mathrm{H}$ NMR exchange spectra for the 4:1 mixture of EC/DMC solvent in NPC with a mixing time of $10 \mu$ s (top) and 100 $\mathrm{ms}$ (bottom). Exchange between the in-pore absorbed and surface adsorbed solvent environments are clearly observed.

At high DMC loadings (4:1) in-pore, surface and free environments were observed (Table 1). The slight decrease in the diffusion coefficient for the "free" $\mathrm{DMC}\left(\mathrm{D} / \mathrm{D}_{0} \sim 0.85\right)$ shows that this free solvent actually has some restriction to translational motion within the material. The in-pore DMC shows a very slight increase with $\mathrm{D} / \mathrm{D}_{0} \sim 0.24$ in comparison to the $1: 1$ material. This change is most likely related to a partial averaging of in-pore, surface and free diffusion rates during the time scale of the PFG NMR experiment. Due to the broadness of the surface DMC resonance we were unable to extract a reliable diffusion constant for this environment.

Figure 6 (blue) shows the ${ }^{1} \mathrm{H}$ DOSY plot of the $1: 1$ (EC/DMC):NPC sample, allowing both the EC and DMC diffusion rates to be evaluated (Table 1). The DOSY shows a continuum of diffusion rates across the EC chemical shift range. This could arise from the EC in-pore diffusion rates being poresize dependent, but may also be an artifact caused by the spectral overlap of EC and DMC and the inability of the analysis software to cleanly separate the individual diffusion constants. Future work to address this issue is ongoing. The in-pore $\mathrm{EC}$ and $\mathrm{DMC}$ solvents both show a reduction in $\mathrm{D} / \mathrm{D}_{0}$, but the $\mathrm{DMC}\left(\mathrm{D} / \mathrm{D}_{0} \sim\right.$ $0.49)$ has a smaller reduction than $\mathrm{EC}\left(\mathrm{D} / \mathrm{D}_{0} \sim 0.21\right)$ for these $1: 1$ $\mathrm{EC} / \mathrm{DMC}$ systems. This result shows that there is a difference in the DMC pore interactions in comparison to EC in NPC. It should be noted that for the mixtures $\mathrm{D}_{0}$ is the diffusion rate for the neat 1:1 EC/DMC solvent.

The diffusion results can also be used in discussing the NPC electrochemical performance. Electrical impedance studies have revealed subtle differences in EDLC efficiency based on the solvent used. It has been suggested that differences in the frequency response (series resistance, series capacitance and phase angle) were the result of variations in the solvent viscosity [50]. The NMR-measured solvent diffusion results reported here reveals that it may not simply be the viscosity of the solvent, but instead the effective or local viscosity of the solvent absorbed within the pores of the material and differences of the in-pore to in-pore exchange rates. Diffusion capacitance is known to be a critical factor in the performance of EDLCs [21,22]. These effects would be particularly noticeable at high device current densities where the solvents' relative inter/intra-pore diffusion rates become critical. The NMR results also showed the reductions of the in-pore diffusion rates were different for EC and DMC, and could possibly impact the transport of electrolyte ions if the solvent species are directly involved in the ion solvation sphere.

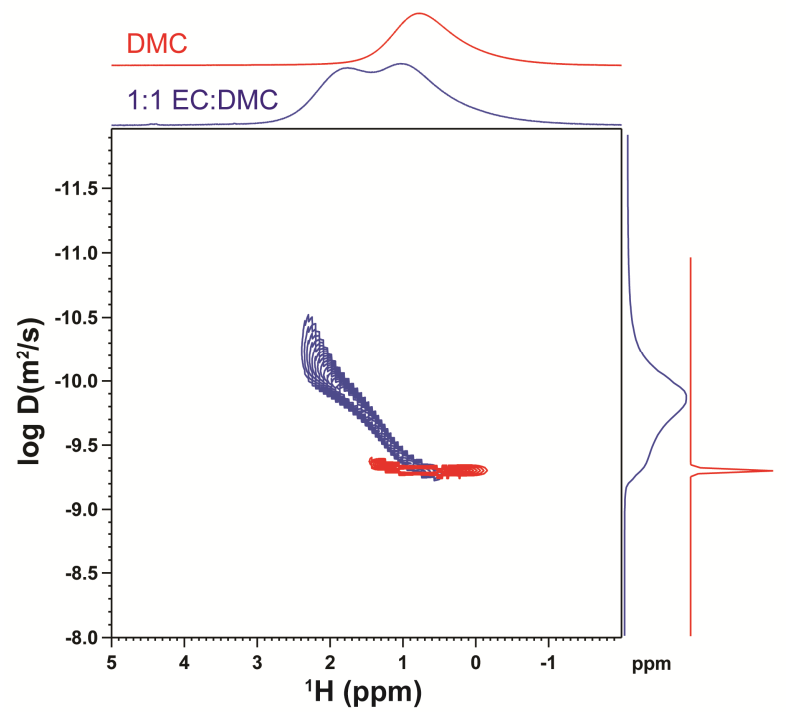

Figure 6: $2 \mathrm{D}{ }^{1} \mathrm{H}$ DOSY for the 1:1 DMC:NPC (red) and the $1: 1$ (EC/DMC):NPC (blue) mixtures. The top projections are the $1 \mathrm{D}{ }^{1} \mathrm{H}$ NMR spectra while the diffusion projections are shown on the right.

\section{Conclusions}

In this paper, the use of ${ }^{1} \mathrm{H}$ HRMAS NMR for the measurement of different types of solvent transport within the pores of NPC materials was demonstrated. The improved spectral resolution afforded under HRMAS allowed the identification and measurement of individual chemical shifts, exchange rates, and diffusion rates for the different components in a carbonate solvent mixture. The ability to determine individual solvent diffusion in mixtures is a result not readily obtained using other diffusion measurement techniques. These NMR studies also provided the rate of solvent transport between pores, and the rate for surface to in-pore exchange. These results provide additional insight into the transport properties of solvents within NPC and may contribute important details into the differences controlling EDLC performance. 
Table 1. ${ }^{1}$ H NMR chemical shifts and PFG self-diffusion coefficients for EC/DMC mixtures absorbed in NPC at $298 \mathrm{~K}$.

\begin{tabular}{|c|c|c|c|c|c|c|c|}
\hline Solvent & Sample & Conditions & $\delta \underset{(\mathbf{H z})]}{(\mathbf{p p m})[\mathrm{FWHM}}$ & Assignment & NICS & $\mathrm{D}\left(\mathrm{m}^{2} / \mathrm{s}\right)$ & $\mathbf{D} / \mathbf{D}_{\mathbf{0}}$ \\
\hline DMC & Neat & $\begin{array}{l}\text { Static } \\
4 \mathrm{kHz}\end{array}$ & $\begin{array}{c}3.65[80] \\
3.61[5]\end{array}$ & Free & -- & $2.7 \pm 0.1 \cdot 10^{-9}$ & -- \\
\hline $\mathrm{EC}$ & Neat, $315 \mathrm{~K}^{\mathrm{b}}$ & & & Free & -- & $1.9 \pm 0.2 \cdot 10^{-y}$ & \\
\hline DMC & 1:1 DMC:NPC & $\begin{array}{l}\text { Static } \\
4 \mathrm{kHz}\end{array}$ & $\begin{array}{c}0.91[1837]^{\mathrm{a}} \\
0.56[540]^{\mathrm{a}}\end{array}$ & In-pore & -3.05 & $5.6 \pm 0.2 \cdot 10^{-10}$ & 0.21 \\
\hline $\mathrm{DMC}$ & 4:1 DMC:NPC & $4 \mathrm{kHz}$ & $\begin{array}{l}3.61[\sim 17] \\
3.04[\sim 825] \\
1.72[\sim 850] \\
\end{array}$ & $\begin{array}{l}\text { Free } \\
\text { Surface } \\
\text { In-pore }\end{array}$ & $\begin{array}{l}-0.47 \\
-1.89 \\
\end{array}$ & $\begin{array}{c}2.3 \pm 0.2 \cdot 10^{-9} \\
-- \\
6.6 \pm 0.2 \cdot 10^{-10} \\
\end{array}$ & $\begin{array}{c}0.85 \\
-- \\
0.24 \\
\end{array}$ \\
\hline DMC & $1: 1 \mathrm{EC} / \mathrm{DMC}$ & $\begin{array}{l}\text { Static } \\
4 \mathrm{kHz}\end{array}$ & $\begin{array}{c}3.68[59] \\
3.64[8]\end{array}$ & Free & -- & $1.05 \pm 0.1 \cdot 10^{-9}$ & -- \\
\hline $\mathrm{EC}$ & $1: 1 \mathrm{EC} / \mathrm{DMC}$ & $\begin{array}{l}\text { Static } \\
4 \mathrm{kHz}\end{array}$ & $\begin{array}{l}4.48[57] \\
4.45[58]\end{array}$ & Free & -- & $8.5 \pm 0.1 \cdot 10^{-10}$ & -- \\
\hline DMC & 1:1 (EC/DMC):NPC & $4 \mathrm{kHz}$ & $0.94[\sim 570]^{\mathrm{a}}$ & In-pore & -2.70 & $5.1 \pm 0.1 \cdot 10^{-10}$ & 0.49 \\
\hline $\mathrm{EC}$ & 1:1 (EC/DMC):NPC & $4 \mathrm{kHz}$ & $1.34[\sim 480]^{\mathrm{a}}$ & In-pore & -3.11 & $1.8 \pm 0.1 \cdot 10^{-10}$ & 0.21 \\
\hline
\end{tabular}

\begin{tabular}{|c|c|c|c|c|c|c|c|}
\hline DMC & 4:1 (EC/DMC):NPC & $4 \mathrm{kHz}$ & $\begin{array}{c}3.61[13] \\
3.31[905] \\
0.98[643]\end{array}$ & $\begin{array}{l}\text { Free } \\
\text { Surface } \\
\text { In-pore }\end{array}$ & $\begin{array}{l}-0.33 \\
-2.66\end{array}$ & 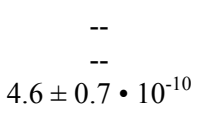 & 0.44 \\
\hline EC & 4:1 (EC/DMC):NPC & $4 \mathrm{kHz}$ & $\begin{array}{l}4.46[20] \\
4.41[23] \\
4.43[510] \\
1.89[378]\end{array}$ & $\begin{array}{l}\text { Free } \\
\text { Free } \\
\text { Surface } \\
\text { In-Pore }\end{array}$ & $\begin{array}{l}-- \\
-- \\
-0.02 \\
-2.56\end{array}$ & $\begin{array}{c}-- \\
-- \\
-\overline{-} \\
2.0 \pm 0.6 \cdot 10^{-10}\end{array}$ & 0.24 \\
\hline
\end{tabular}

${ }^{a}$ Asymmetric line shape, Baycenter reported for $\delta$ and FWHM.

[13] S.R. Sivakkumar, J.Y. Nerkar, A.G. Pandolfo,

${ }^{\mathrm{b}}$ Elevated temperature required due to the high MP of EC.

[14] W. Gu, G. Yushin, Wiley Interdiscip. Rev.: Energy

\section{Acknowledgments}

Sandia is a multiprogram laboratory operated by Sandia Corporation, a Lockheed Martin Company, of the United States Department of Energy's National Nuclear Security Administration under Contract DE-AC04-94AL85000. This work was partially funded by Sandia's LDRD program. The authors also acknowledge Eric Coker (Sandia) for providing the $\mathrm{N}_{2}$ and Ar BET absorption data.

\section{References and notes}

[1] I. Hadjipaschalis, A. Poullikkas, V. Efthimiou, Renew. Sust. Energy Rev. 13 (2009) 1513.

[2] D.O. Akinyele, R.K. Rayudu, Sustainable Energy Technologies and Assessments 8 (2014) 74.

[3] M. Yekini Suberu, M. Wazir Mustafa, N. Bashir, Renew. Sust. Energy Rev. 35 (2014) 499.

[4] P. Simon, Y. Gogotsi, B. Dunn, Science 343 (2014) 1210.

[5] G.G. Amatucci, F. Badway, A. Du Pasquier, T. Zheng, J. Electrochem. Soc. 148 (2001) A930.

[6] S.R. Sivakkumar, A.G. Pandolfo, Electrochim. Acta 65 (2012) 280.

[7] M. Yuan, W. Liu, Y. Zhu, Y. Xu, Russ J Electrochem 50 (2014) 594.

[8] A.D. Pasquier, I. Plitz, J. Gural, F. Badway, G.G. Amatucci, J. Power Sources 136 (2004) 160.

[9] A. Laheäär, H. Kurig, A. Jänes, E. Lust, Electrochim. Acta 54 (2009) 4587.

[10] D. Aurbach, B. Markovsky, A. Shechter, Y. Ein-Eli, H. Cohen, J. Electrochem. Soc. 143 (1996).

[11] B. Ferrer, M. Alvaro, H. Garcia, in: A. Mohammad (Ed.), Green Solvents I, Springer Netherlands, 2012, p. 363.

[12] P. Simon, Y. Gogotsi, Nat. Mater. 7 (2008) 845.
[15] M.-H. Kim, K.-B. Kim, S.-M. Park, K.C. Roh, Scientific Reports 6 (2016) 21182.

[16] P.J.F. Harris, Crit. Rev. Solid State Mater. Sci. 30 (2005) 235.

[17] A. Geim, K. Novoselov, Nat. Mater. 6 (2007) 183.

[18] C. Pean, B. Daffos, B. Rotenberg, P. Levitz, M. Haefele, P.-L. Taberna, P. Simon, M. Salanne, J. Am. Chem. Soc. 137 (2015) 12627.

[19] A. Kajdos, A. Kvit, F. Jones, J. Jagiello, G. Yushin, J. Am. Chem. Soc. 132 (2010) 3252.

[20] J.M. Griffin, A.C. Forse, C.P. Grey, Solid State Nucl. Magn. Reson. 74-75 (2016) 16.

[21] J. Kang, J. Wen, S.H. Jayaram, A. Yu, X. Wang, Electrochim. Acta 115 (2014) 587.

[22] S. Gao, K. Wang, Z. Du, Y. Wang, A. Yuan, W. Lu, L. Chen, Carbon 92 (2015) 254.

[23] S. Urbonaite, J.M. Juárez-Galán, J. Leis, F. RodríguezReinoso, G. Svensson, Microporous Mesoporous Mater. 113 (2008) 14.

[24] A.G. Pandolfo, A.F. Hollenkamp, J. Power Sources 157 (2006) 11 .

[25] J. Luo, H.D. Jang, J. Huang, ACS Nano 7 (2013) 1464.

[26] M. Deschamps, E. Gilbert, P. Azais, E. Raymundo-Piñero, M. Ammar, P. Simon, D. Massiot, F. Béguin, Nat. Mater. 12 (2013).

[27] A.C. Forse, J.M. Griffin, C. Merlet, P.M. Bayley, H. Wang, P. Simon, C.P. Grey, J. Am. Chem. Soc. 137 (2015) 7231.

[28] A.C. Forse, J.M. Griffin, V. Presser, Y. Gogotsi, C.P. Grey, J. Phys. Chem. C 118 (2014) 7508.

[29] A.C. Forse, J.M. Griffin, H. Wang, N.M. Trease, V. Presser, Y. Gogotsi, P. Simon, C.P. Grey, Phys. Chem. Chem. Phys. 15 (2013) 7722.

[30] A.C. Forse, C. Merlet, P.K. Allan, E.K. Humphreys, J.M. Griffin, M. Aslan, M. Zeiger, V. Presser, Y. Gogotsi, C.P. Grey, Chem. Mater. 27 (2015) 6848. 
[31] Y.-Z. Xing, Z.-X. Luo, A. Kleinhammes, Y. Wu, Carbon 77 (2014) 1132.

[32] L. Borchardt, M. Oschatz, S. Paasch, S. Kaskel, E. Brunner, Phys. Chem. Chem. Phys. 15 (2013).

[33] T. Kim, K. Ideta, D. Jung, K. Saito, J.-I. Park, C. Rhee, J. Miyawaki, I. Mochida, S.-H. Yoon, RSC Advances 4 (2014).

[34] Z.-X. Luo, Y.-Z. Xing, Y.-C. Ling, A. Kleinhammes, Y. $\mathrm{Wu}$, Nat. Commun. 6 (2015).

[35] Z.-X. Luo, Y.-Z. Xing, S. Liu, Y.-C. Ling, A. Kleinhammes, Y. Wu, J. Phys. Chem. Lett. 6 (2015) 5022.

[36] T. Alam, J. Jenkins, HR-MAS NMR Spectroscopy in Material Science in M.A. Farrukh (Ed.), Advanced Aspects of Spectroscopy. InTech, 2012, p. 279.

[37] D.L. Vanderhart, W.L. Earl, A.N. Garroway, Journal of Magnetic Resonance (1969) 44 (1981) 361.

[38] E.O. Stejskal, J.E. Tanner, J. Chem. Phys. 42 (1965) 288.

[39] P.T. Callaghan, Translational dynamics and magnetic resonance: principles of pulsed gradient spin echo NMR, Oxford University Press, 2011.

[40] O.N. Kalugin, V.V. Chaban, V.V. Loskutov, O.V. Prezhdo, Nano Lett. 8 (2008) 2126.

[41] F. Furtado, P. Galvosas, M. Gonçalves, F.D. Kopinke, S. Naumov, F. Rodríguez-Reinoso, U. Roland, R. Valiullin, J. Kärger, Microporous Mesoporous Mater. 141 (2011) 184191.

[42] M. Krutyeva, F. Grinberg, F. Furtado, P. Galvosas, J. Kärger, A. Silvestre-Albero, A. Sepulveda-Escribano, J. Silvestre-Albero, F. Rodríguez-Reinoso, Microporous Mesoporous Mater. 120 (2009) 9197.
[43] H. Herden, J. Kärger, H. Pfeifer, C. Kube, R. Schöllner, J. Colloid Interface Sci. 152 (1992) 281.

[44] Y. Maletin, P. Novak, E. Shembel, V. Izotov, N. Strizhakova, A. Mironova, V. Danilin, S. Podmogilny, Appl. Phys. A 82 (2005) 653.

[45] Y. Maletin, V. Strelko, N. Stryzhahkova, S. Zelinsky, A.B. Rozhenko, D. Gromadsky, V. Volkov, S. Tychina, O. Gozhenko, D. Drobny, Energy Environmental Research 3 (2013) 156

[46] L.L. Latour, P.P. Mitra, R.L. Kleinberg, C.H. Sotak, J. Magn. Reson. A 101 (1993) 342.

[47] Z.-X. Luo, J. Paulsen, M. Vembusubramanian, Y.-Q. Song, Geophysics 80 (2015) E41.

[48] D. Massiot, F. Fayon, M. Capron, I. King, S. Le Calvé, B. Alonso, J.O. Durand, B. Bujoli, Z. Gan, G. Hoatson, Magn. Reson. Chem. 40 (2002) 70.

[49] C. Merlet, A.C. Forse, J.M. Griffin, D. Frenkel, C.P. Grey, J. Chem. Phys. 142 (2015) 094701.

[50] M. Arulepp, L. Permann, J. Leis, A. Perkson, K. Rumma, A. Jänes, E. Lust, J. Power Sources 133 (2004) 320.

\section{Supplementary Material}

Supplementary data associated with this article can be found, in the online version, at doi:10.1016/j.cplett.XXXXXX. 
Filename: ChemPhysLett_dif_revised_ver2

Directory: $\quad$ C: $\quad$ Users $\quad$ abalolong.SPI-GLOBAL $\backslash$ Documents

Template: $\quad$ C: $\quad$ Documents and Settings $\backslash$ loloughlins $\backslash$ Local Settings $\backslash$ Temporary Internet Files $\backslash$ Content.Outlook $\backslash 20 \mathrm{TG} 5 J L Q \backslash$ TetrahedronLetters (2).dot

Title: Tetrahedron template

Subject:

Author: $\quad$ Sarah O'Loughlin

Keywords:

Comments:

Creation Date: $\quad$ 5/23/2016 3:16:00 PM

Change Number: $\quad 9$

Last Saved On: $\quad$ 6/2/2016 11:02:00 AM

Last Saved By: $\quad$ revier

Total Editing Time: 59 Minutes

Last Printed On: $\quad$ 9/5/2016 11:16:00 PM

As of Last Complete Printing

Number of Pages: 8

Number of Words: $\quad 9,014$ (approx.)

Number of Characters: $\quad 44,079$ (approx.) 